Sādhanā Vol. 38, Part 4, August 2013, pp. 743-760. (C) Indian Academy of Sciences

\title{
A comparative study on the use of drilling and milling processes in hole making of GFRP composite
}

\author{
HUSSEIN M ALI ${ }^{1, *}$, ASIF IQBAL ${ }^{1}$ and LI LIANG ${ }^{2}$ \\ ${ }^{1}$ Department of Mechanical Engineering, Eastern Mediterranean University, \\ Gazimagusa, Northern Cyprus, Via Mersin 10, Turkey \\ ${ }^{2}$ College of Mechanical and Electrical Engineering, Nanjing University of \\ Aeronautics and Astronautics, Nanjing, 210016, China \\ e-mail: hrlha@yahoo.com
}

MS received 26 January 2013; revised 11 June 2013; accepted 27 June 2013

\begin{abstract}
Drilling and milling processes are extensively used for producing riveted and bolted joints during the assembly operations of composite laminates with other components. Hole making in glass fibre reinforced plastic (GFRP) composites is the most common mechanical process, which is used to join them to other metallic structures. Bolt joining effectiveness depends, critically, on the quality of the holes. The quality of machined holes in GFRP is strongly dependent on the appropriate choice of the cutting parameters. The main purpose of the present study is to assess the influence of drilling and milling machining parameters on hole making process of woven laminated GFRP material. A statistical approach is used to understand the effects of the control parameters on the response variables. Analysis of variance (ANOVA) was performed to isolate the effects of the parameters affecting the hole making in the two types of cutting processes. The results showed that milling process is more suitable than drilling process at high level of cutting speed and low level of feed rate, when the cutting quality (minimum surface roughness, minimum difference between upper and lower diameter) is of critical importance in the manufacturing industry, especially for precision assembly operation.
\end{abstract}

Keywords. Laminated GFRP; hole making; drilling; milling; optimization.

\section{Introduction}

Glass fibre-reinforced plastic (GFRP) composite are widely used in many areas. They are used in industrial fields, such as aerospace, aircraft, automobile and sport goods, due to their properties such as high specific strength, high specific modulus of elasticity, light weight, corrosion resistance, etc. (Tsao 2008). As structural materials, joining composite laminates to other metal materials structures could not be avoided (Hufenbach et al 2007) and bolt joining efficiency and

*For correspondence 
quality depend critically on the quality of machined holes. Drilling and milling cutting processes are extensively used for producing riveted and bolted joints during the assembly operation of composite laminates with other components. The life of the joint in the assembled structure can be critically affected by the quality of the holes, so it is necessary to make a precise holes in the components to ensure high joint strength. However, the characteristics of composite laminates such as non-homogeneous, anisotropic, highly abrasive and hard-reinforced fibres make them difficult to be machined (Teti 2002; Abrao et al 2007). The quality of cutting hole in a glass fibre reinforced plastic is strongly dependent on the appropriate choice of the cutting parameters. Many researchers carry out the studies on drilling and milling of composite materials separately. Hocheng \& Tsao (2005) mainly summarized the critical thrust force models of various drill bits for delamination-free drilling of composite laminates developed by themselves, as well as several non-traditional machining processes for composite laminates. Yang et al (2006) have conducted end-milling operation on high purity graphite and they optimized the end milling process parameters such as cutting speed, feed rate and depth of cut for groove width and surface roughness. El-Sonbaty et al (2004) used twist drills with diameters of 8, 9, 10, 11, 12 and $13 \mathrm{~mm}$ to machine GFRP using a constant rotational speed. The results indicated that thrust force and torque increased with drill diameter and feed rate, due to increase in the shear area. Increasing cutting speed also resulted in higher thrust force and torque, however, not to the same extent as when feed rate is elevated. Mohan et al (2005) also studied the effects of drill size and feed on thrust force and torque. Tsao \& Hocheng (2003) investigated the influence of the roundness of the drill on delamination using the theories of mechanics of fracture and energy conservation. They concluded that the run-out of the drill causes increasing in the thrust force and consequently resulting in more severe delamination of the drilled specimen. Ramulu et al (1994) concluded that the surface quality (surface roughness), and delamination factor is strongly dependent on cutting parameters, tool geometry and cutting forces (feed force, depth force and cutting force) in milling of composites. Hocheng et al (1993) studied the effect of the fibre orientation on the cut quality, cutting forces and tool wear. Mohd Ariffin et al (2009) studied the relation between cutting parameters with the damage length of cutting surface of GFRP in drilling process. They used two types of cutting tools. The result shows that the minimum and maximum damage length was $0.05 \mathrm{~mm}$ and $0.44 \mathrm{~mm}$, respectively, for specified cutting parameters. Most of the studies on GFRP machining show that minimizing the thrust force, surface roughness and delamination factor simultaneously is very difficult and is to be controlled.

The current research work presents a comprehensive approach to select optimal cutting parameters for high cut quality, productivity and low cost simultaneously in hole making by drilling and milling of glass fibre reinforced epoxy composite material type 3240. This type of GFRP is mainly used in aerospace, transportation tools and electrical appliances as insulation materials.

Analysis of variance (ANOVA) was performed to investigate the cutting characteristics, and then a numerical optimization approach has been performed using Derringer-Suich multicriteria decision modelling approach. A set of drilling and milling experiments, were conducted, with cutting parameters prefixed on glass fibre reinforced plastic (GFRP) laminate. The input parameters namely hole-diameter, material thickness, cutting speed and feed rate will be optimized based on statistical analyses performed.

\section{Experimental works}

\subsection{Material}

For the experimental study, a sheet of woven laminated glass fibre reinforced plastic (GFRP), Type 3240 produced by Yongchun Material Co. of China was used as shown in figure 1. The 


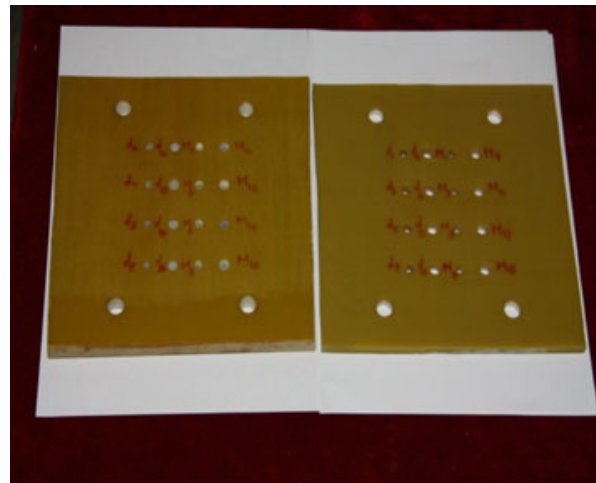

(a)

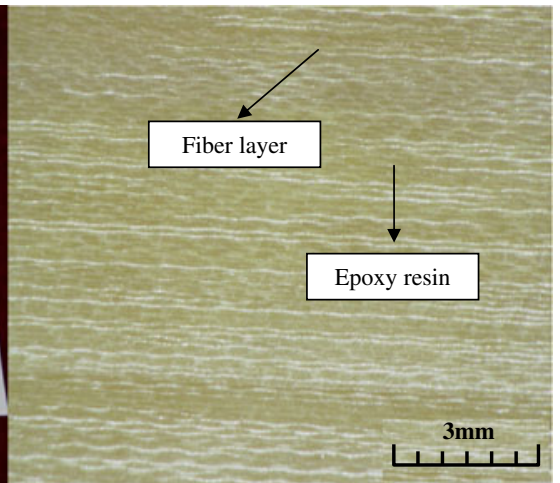

(b)

Figure 1. (a) Laminated GFRP with the two thicknesses. (b) Cross-sectional view of GFRP.

Table 1. Major properties of laminated GFRP type 3240.

\begin{tabular}{llc}
\hline No. & \multicolumn{1}{c}{ Property } & Value $/$ unit \\
\hline 1 & Fiber density in GFRP & $0.82 \mathrm{gm} / \mathrm{cm} 3$ \\
2 & Fiber volume fraction & $45 \%$ \\
3 & Max. working temperature & $200^{\circ} \mathrm{C}$ \\
4 & Average tensile strength & $295.45 \mathrm{MPa}$ \\
5 & Layer thickness & $0.5 \mathrm{~mm}$ \\
\hline
\end{tabular}

GFRP is reinforced with $45 \%$ glass fibre. The major properties of the laminated GFRP material used in the present study are listed in table 1.

\subsection{Design of experiments}

The control parameters are selected according to the available literature, availability of spindle speed and feed rate on the machine. A four factors, two-level, full-factorial design of experiments (24 = 16 tests) was developed for each of the two cutting process. High and low, levels of the control parameters are shown in table 2. The experimental results are presented in tables 3 and 4 .

Table 2. High and low setting of control parameters in both drilling and milling process.

\begin{tabular}{llccc}
\hline Code & \multicolumn{1}{c}{ Input factor } & Unit & Level 1 & Level 2 \\
\hline $\mathrm{A}$ & Material thickness & $\mathrm{mm}$ & 8 & 16 \\
$\mathrm{~B}$ & Cutting speed & $\mathrm{m} / \mathrm{min}$ & 24 & 48 \\
$\mathrm{C}$ & Feed rate (drilling) & $\mathrm{mm} / \mathrm{rev}$ & 0.06 & 0.09 \\
& Feed rate (milling) & $\mathrm{mm} / \mathrm{tooth}$ & 0.06 & 0.09 \\
$\mathrm{D}$ & Nominal hole diameter & $\mathrm{mm}$ & 6 & 8 \\
\hline
\end{tabular}




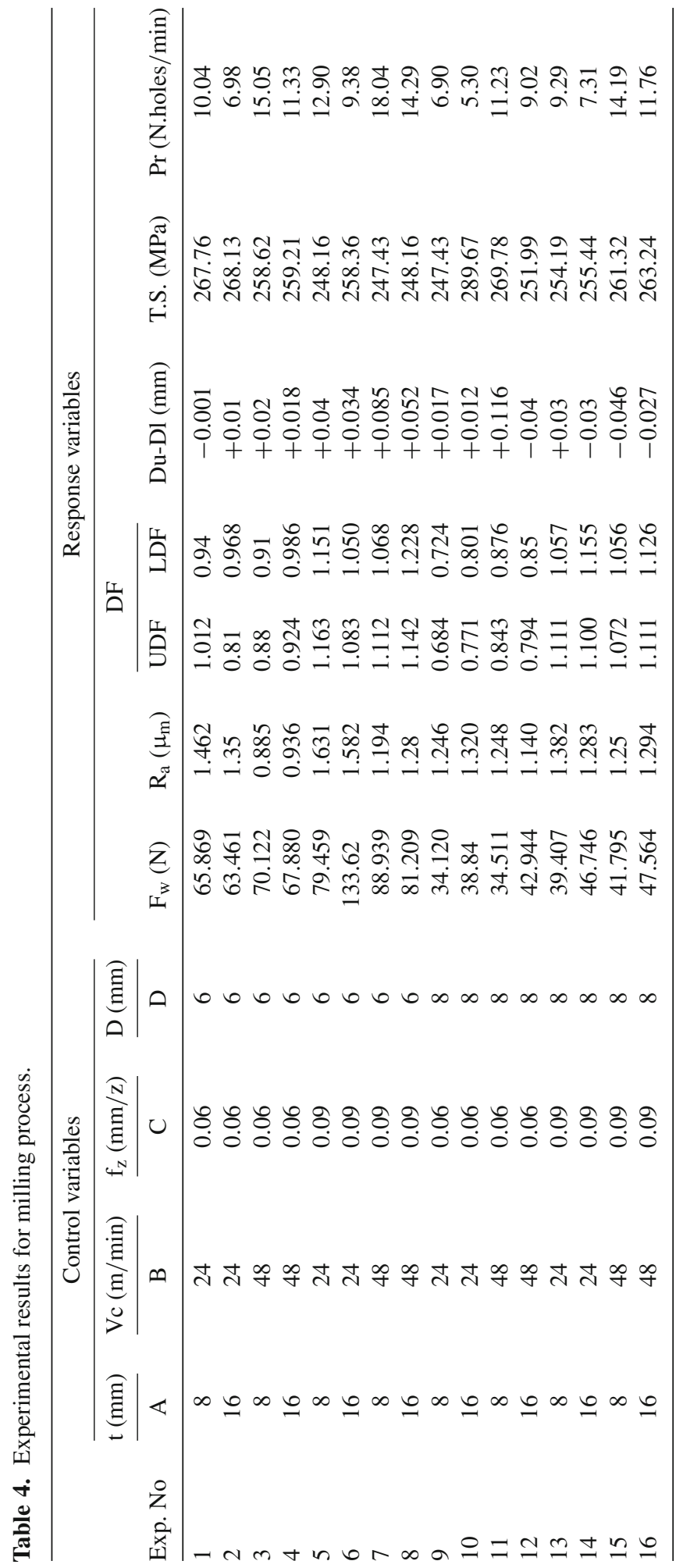


The following is the description of the response variables (performance measures) to be measured in 32 tests:

(i) The arithmetic mean surface roughness (centre line average) $\left(\mathrm{R}_{\mathrm{a}}\right)$, being the widely used parameter in the industries for machining process. It was measured using a contact-type stylus Mahr Perth meter. The measurements were taken at four different locations along the cut hole depth surface-measured in microns. Then, the average value is reported for the analysis.

(ii) Delamination factor at the upper and lower surfaces around the hole. Delamination factor (DF) is defined by the ratio of maximum diameter (of damage zone around hole) to the actual diameter to be drilled (D),

$$
\mathrm{D}_{\mathrm{F}=} \mathrm{D}_{\max } \cdot / \mathrm{D}
$$

Both upper and lower maximum diameters $\left(\mathrm{D}_{\max }\right)$ in the damage around each hole for each specimen were measured by using optical microscope type Leica DVM500. Higher values of delamination factor represent high surface damage.

(iii) Thrust force $\left(\mathrm{F}_{\mathrm{Z}}\right)$ in case of drilling is the force acting along the hole depth during the cutting process. Machining force $\left(\mathrm{F}_{\mathrm{W}}\right)$ in the case of milling process is calculated according to the following equation:

$$
\mathrm{F}_{\mathrm{w}}=\sqrt{F x^{2}+F y^{2}+F z^{2}}
$$

where $F_{x}, F_{y}$ and $F_{z}$ are the three orthogonal components of machining force which were measured using a piezoelectric dynamometer.

(iv) Tensile strength, measured in MPa. 32 tensile test of hole specimens (16 holes cut each by drilling and milling) according to (ASTM D5766) was carried out using Universal Tensile Testing Machine, Type WDW-300, made by Changchun Kexin Com./China. Figure 2 shows this set-up http://www.ptli.com/testopedia.

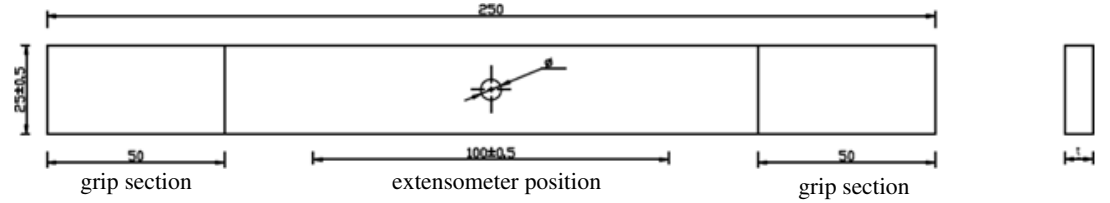

(a)

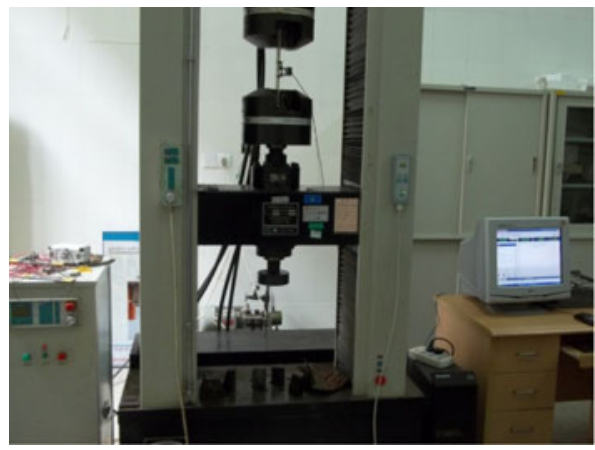

(b)

Figure 2. (a) Standard holed-specimen for tensile test. (b) Universal tensile testing machine. 
(v) Productivity (Pr) that represents a number of holes cut per minutes.

The productivity calculation for drilling cutting is given by

$$
\begin{aligned}
\text { No. of holes per minute }= & 1 /[\text { material thickness to be cut }(\mathrm{mm}) / \mathrm{feed}(\mathrm{mm} / \mathrm{min})] \\
& +(\text { tool positioning }+ \text { retraction time })
\end{aligned}
$$

The productivity calculation for milling cutting is given by

$$
\begin{aligned}
\text { No. of holes per minute }= & 1 / \text { feed }(\mathrm{mm} / \mathrm{min})[\text { material thickness to be cut }(\mathrm{mm}) \\
& +(1+3.14)(\mathrm{D}-\mathrm{Dm})] \\
& +(\text { tool positioning }+ \text { retraction time })
\end{aligned}
$$

\subsection{Experimental set-up}

The drilling and milling experiments were conducted on CNC Vertical Machining Center, type TH5 $660 \mathrm{~A}$ with $7.5 \mathrm{~kW}$ spindle power and a maximum spindle speed of $5300 \mathrm{rpm}$. In all the tests, the cutting tools used were HSS, 6 and $8 \mathrm{~mm}$ diameters drills and 5 and $6 \mathrm{~mm}$ diameters cemented carbide end mills. The advantage of using cemented carbide drills over HSS is
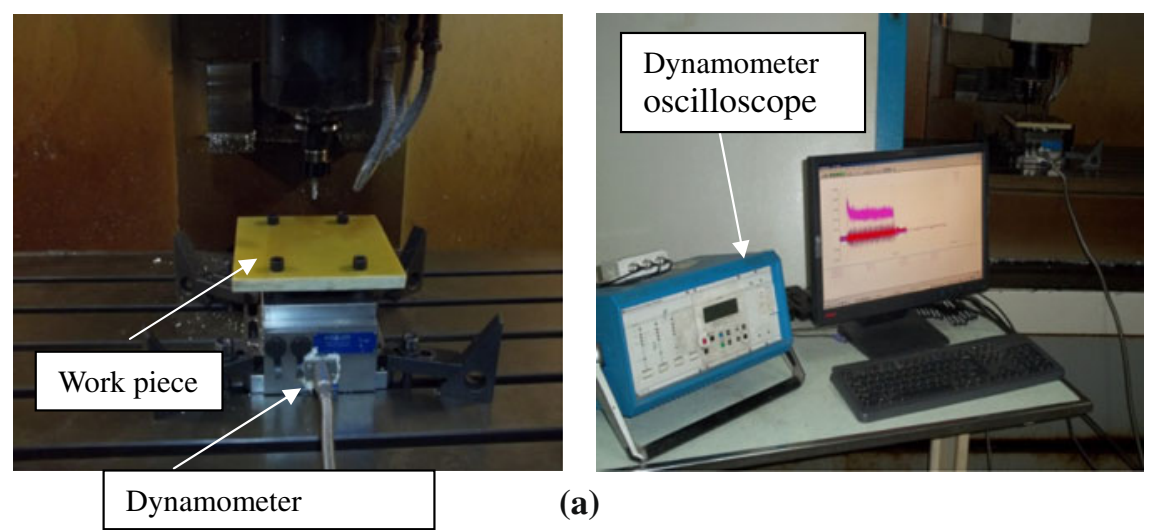

(a)

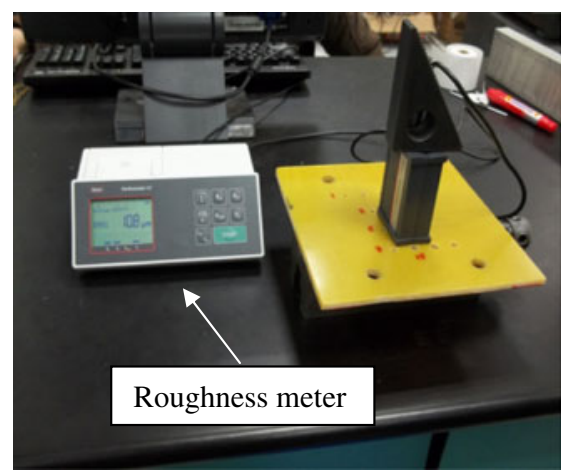

(b)

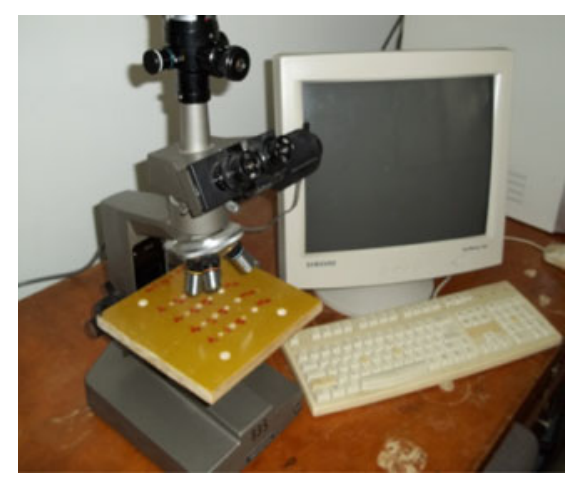

(c)

Figure 3. Experimental set-up. (a) Fixation of work piece on vertical machining center with kistler dynamometer and its oscilloscope. (b) Surface roughness measurement set-up. (c) Optical microscope measurement set-up. 
its strength to withstand cutting forces and the low cost of the tool. From the tool life point of view, HSS performs very well at intermittent cutting applications. However, the greatest limitation of HSS is that it's usable cutting speed range is far lower when compared to cemented carbide. The dimensions of the work piece material to be cut were $200 \mathrm{~mm} \times 200 \mathrm{~mm} \times 8 \mathrm{~mm}$ and $200 \mathrm{~mm} \times 200 \mathrm{~mm} \times 16 \mathrm{~mm}$. A multi component piezoelectric dynamometer type $9256 \mathrm{C}$ Kistler with a load amplifier was used to acquire the three orthogonal components of machining forces on the work pieces. Arithmetic surface roughness $\left(R_{a}\right)$ taken along the depth of cutting hole at four points was measured by Mahr Perth meter M1 according to ISO 4287. Optical Microscope type Leica DVM500, having accuracy $0.001 \mathrm{~mm}$ was used to measure the cut profile. The experimental set-up with the cutting tools is presented in figure 3 .

\section{Results, analyses and discussions}

The quality of cutting hole by drilling and milling process was evaluated by the response parameters such as surface roughness, delamination factor and difference between upper and lower diameter. Tables 3 and 4 present the results obtained from 16 tests each by drilling and milling processes. Experimental data were analysed using ANOVA (Analysis of Variance) and numerical optimization was performed using Derringer-Suich multi-criteria decision modelling approach. ANOVA is a basic statistical technique for determining the proportion of influence of an input parameter or set of input parameters on total variation of response parameter(s). In Derringer-Suich, multi-criteria optimization technique different desirability functions are assigned to maximization/minimization of different response parameters (variables). Further details can be found from reference (Derringer \& Suich 1980). All the statistical analyses, including ANOVA and numerical optimization, were performed using commercial statistical software called Design-Expert $($. The details are presented in upcoming sub-sections.

\subsection{Analysis of variance}

The effects of all the individual input variables have been shown in ANOVA tables. The effects of all the possible interactions among the input variables were analyzed and only the significant

Table 5. ANOVA details for surface roughness (Ra), average thrust force (Fz), tensile strength (T.S.) and identification of significant input parameters in drilling.

\begin{tabular}{|c|c|c|c|c|c|c|}
\hline \multirow[b]{2}{*}{ Source } & \multicolumn{2}{|c|}{$\mathrm{R}_{\mathrm{a}}$} & \multicolumn{2}{|c|}{$\mathrm{F}_{\mathrm{z}}$} & \multicolumn{2}{|c|}{ T.S. } \\
\hline & F-value & P-value & F-value & P-value & F-value & $\mathrm{P}$-value \\
\hline Model & 22.14 & 0.0016 & 50.06 & 0.0002 & 0.99 & 0.5398 \\
\hline $\mathrm{A}-(\mathrm{t})$ & 3.37 & 0.1258 & 5.29 & 0.0699 & 0.59 & 0.4777 \\
\hline B-(V) & 80.90 & 0.0003 & 14.49 & 0.0125 & 0.47 & 0.5243 \\
\hline$C-\left(f_{z}\right)$ & 106.82 & 0.0001 & 138.98 & 0.0001 & 0.64 & 0.4589 \\
\hline D-(D) & 6.47 & 0.0517 & 282.86 & 0.0001 & 3.84 & 0.1074 \\
\hline $\mathrm{A} \times \mathrm{B}$ & 0.3132 & 0.3132 & 0.18 & 0.6913 & 0.5870 & 0.5870 \\
\hline $\mathrm{A} \times \mathrm{C}$ & 0.6076 & 0.6076 & 2.09 & 0.2078 & 0.4807 & 0.4807 \\
\hline$A \times D$ & 0.0192 & 0.0192 & 12.15 & 0.0176 & 0.5545 & 0.5545 \\
\hline $\mathrm{B} \times \mathrm{C}$ & 0.8129 & 0.8129 & 5.91 & 0.0593 & 0.2653 & 0.2653 \\
\hline $\mathrm{B} \times \mathrm{D}$ & 0.8513 & 0.8513 & 5.11 & 0.0733 & 0.3530 & 0.3530 \\
\hline $\mathrm{C} \times \mathrm{D}$ & 0.0225 & 0.0225 & 33.57 & 0.0022 & 0.5433 & 0.5433 \\
\hline
\end{tabular}


Table 6. ANOVA details for upper and lower delamination factor and difference between upper and lower diameter and identification of significant input parameters in the drilling process.

\begin{tabular}{|c|c|c|c|c|c|c|}
\hline \multirow[b]{2}{*}{ Source } & \multicolumn{2}{|c|}{ UDF } & \multicolumn{2}{|c|}{ LDF } & \multicolumn{2}{|c|}{$\mathrm{D}_{\mathrm{u}}-\mathrm{D}_{\mathrm{L}}$} \\
\hline & F-value & P-value & F-value & P-value & F-value & P-value \\
\hline Model & 69.44 & 0.0001 & 74.48 & 0.0001 & 4.86 & 0.0475 \\
\hline $\mathrm{A}-(\mathrm{t})$ & 0.15 & 0.7161 & 2.40 & 0.1824 & 4.85 & 0.0789 \\
\hline B-(V) & 50.56 & 0.0009 & 66.40 & 0.0005 & 0.35 & 0.5808 \\
\hline C- $\left(f_{z}\right)$ & 638.88 & 0.0001 & 669.16 & 0.0001 & 2.84 & 0.1530 \\
\hline D-(D) & 0.41 & 0.5494 & 2.91 & 0.1488 & 10.69 & 0.0222 \\
\hline$A \times B$ & 0.11 & 0.7541 & 1.93 & 0.2233 & 0.78 & 0.4182 \\
\hline $\mathrm{A} \times \mathrm{C}$ & 3.55 & 0.1183 & 0.081 & 0.7876 & 5.13 & 0.0729 \\
\hline$A \times D$ & 0.43 & 0.5414 & 1.44 & 0.2838 & 10.68 & 0.0222 \\
\hline $\mathrm{B} \times \mathrm{C}$ & 1.140 & 0.9744 & 0.100 & 0.7649 & 5.16 & 0.0722 \\
\hline$B \times D$ & 0.26 & 0.6341 & 0.32 & 0.5943 & 7.15 & 0.0441 \\
\hline $\mathrm{C} \times \mathrm{D}$ & 0.016 & 0.9029 & 0.016 & 0.9044 & 0.94 & 0.3774 \\
\hline
\end{tabular}

interactions have been shown in the plots. This is to be mentioned, with respect to ANOVA table, that effect of any parameter is considered to be significant if $p$-value $\leq 0.05$; and insignificant otherwise. As there are many input and responsible variables included in this study for both drilling and milling process, it means a large number of ANOVA tables will take a big space, for that reason, only $\mathrm{F}$ and $\mathrm{P}$ values were included in the tables (i.e. tables 5, 6, 7 and 8). $\mathrm{F}$-value is the ratio between mean square of the input parameter to the mean square of error while, P-value is the probability of a test statistics. It is the lowest level of significance that would lead to rejection of the null hypothesis. The bold numbers of p-values represent the significant parameters and insignificant if otherwise. In ANOVA analysis, two points are used to define the effect of a factor. The effect of a factor is defined to be the change in the response produced by the change in the level of the factor. It is better to join the two points with straight line because it is unknown how the values between the recorded points may.

Table 7. ANOVA details for Ra, Fw and T.S. and identification of significant input parameters in milling process.

\begin{tabular}{lcccccccc}
\hline & \multicolumn{2}{c}{$\mathrm{R}_{\mathrm{a}}$} & & \multicolumn{2}{c}{$\mathrm{F}_{\mathrm{w}}$} & & \multicolumn{2}{c}{ T.S. } \\
\cline { 2 - 3 } Source & F-value & P-value & & F-value & P-value & & F-value & P-value \\
\hline Model & 11.53 & $\mathbf{0 . 0 0 7 3}$ & & 70.71 & $\mathbf{0 . 0 0 0 1}$ & & 0.76 & 0.666 \\
$\mathrm{~A}-(\mathrm{T})$ & 0.17 & 0.6983 & & 2.90 & 0.1491 & & 0.67 & 0.449 \\
$\mathrm{~B}-(\mathrm{Vc})$ & 54.37 & $\mathbf{0 . 0 0 0 7}$ & & 4.03 & 0.1010 & & 0.37 & 0.568 \\
$\mathrm{C}-\left(\mathrm{f}_{\mathrm{z}}\right)$ & 22.63 & $\mathbf{0 . 0 0 5 1}$ & & 67.73 & $\mathbf{0 . 0 0 0 4}$ & & 2.51 & 0.173 \\
$\mathrm{D}-(\mathrm{D})$ & 0.33 & 0.5930 & & 608.01 & $\mathbf{0 . 0 0 0 1}$ & & 0.60 & 0.474 \\
$\mathrm{~A} \times \mathrm{B}$ & 0.89 & 0.3898 & & 0.90 & 0.3870 & & 2.03 & 0.213 \\
$\mathrm{~A} \times \mathrm{C}$ & 0.078 & 0.7908 & & 0.033 & 0.8621 & & 0.055 & 0.823 \\
$\mathrm{~A} \times \mathrm{D}$ & 0.056 & 0.8226 & & 8.97 & $\mathbf{0 . 0 3 0 3}$ & & 0.11 & 0.757 \\
$\mathrm{~B} \times \mathrm{C}$ & 1.26 & 0.3125 & & 0.12 & 0.7414 & & 0.60 & 0.472 \\
$\mathrm{~B} \times \mathrm{D}$ & 27.05 & 0.0035 & & 0.40 & 0.5569 & & 0.35 & 0.578 \\
$\mathrm{C} \times \mathrm{D}$ & 8.43 & $\mathbf{0 . 0 3 3 6}$ & & 13.99 & $\mathbf{0 . 0 1 3 4}$ & & 0.31 & 0.599 \\
\hline
\end{tabular}


Table 8. ANOVA details for UDF, LDF and DU-DL and identification of significant input parameters in milling process.

\begin{tabular}{lcccccccc}
\hline & \multicolumn{2}{c}{ UDF } & & \multicolumn{2}{c}{ LDF } & & \multicolumn{2}{c}{ Du- $\mathrm{D}_{\mathrm{L}}$} \\
\cline { 2 - 3 } Source & F-value & P-value & & F-value & P-value & & F-value & P-value \\
\hline Model & 7.53 & $\mathbf{0 . 0 1 9}$ & & 4.90 & $\mathbf{0 . 0 4 6}$ & & 5.07 & $\mathbf{0 . 0 4 3}$ \\
A-(T) & 0.27 & 0.624 & & 1.67 & 0.252 & & 0.032 & 0.864 \\
$\mathrm{~B}-(\mathrm{Vc})$ & 0.28 & 0.619 & & 0.74 & 0.429 & & 13.47 & 0.014 \\
$\mathrm{C}-\left(\mathrm{f}_{\mathrm{z}}\right)$ & 63.78 & $\mathbf{0 . 0 0 0 5}$ & & 38.65 & $\mathbf{0 . 0 0 1}$ & & 11.51 & $\mathbf{0 . 0 1 9}$ \\
$\mathrm{D}-(\mathrm{D})$ & 5.52 & 0.065 & & 4.93 & 0.077 & & 3.03 & 0.142 \\
$\mathrm{~A} \times \mathrm{B}$ & 0.98 & 0.367 & & 0.36 & 0.573 & & 3.18 & 0.134 \\
$\mathrm{~A} \times \mathrm{C}$ & 0.13 & 0.733 & & 0.059 & 0.817 & & 0.78 & 0.418 \\
$\mathrm{~A} \times \mathrm{D}$ & 1.01 & 0.360 & & 0.036 & 0.857 & & 2.43 & 0.179 \\
$\mathrm{~B} \times \mathrm{C}$ & 0.46 & 0.529 & & 0.18 & 0.692 & & 5.42 & 0.067 \\
$\mathrm{~B} \times \mathrm{D}$ & 0.36 & 0.573 & & 0.089 & 0.777 & & 0.35 & 0.581 \\
$\mathrm{C} \times \mathrm{D}$ & 2.47 & 0.177 & & 2.32 & 0.188 & & 10.52 & $\mathbf{0 . 0 2 2}$ \\
\hline
\end{tabular}

3.1a Analysis and discussion of hole making by drilling: Tables 5 and 6 present ANOVA performed on the data related to the response variables for the drilling process.

The columns F-value and p-value in table 5, suggest that effects of cutting speed, feed rate, interaction between material thickness and nominal hole diameter and the interaction between feed rate and nominal hole diameter upon arithmetic surface roughness are significant. Cutting speed, feed rate, hole diameter, interaction between material thickness and hole diameter and the interaction between feed rate and hole diameter are significant factors upon the thrust force. The analysis shows that there is no significant factor upon tensile strength. Table 6 , shows that cutting speed and feed rate are influential factors on delamination at the upper and lower surface while the difference between upper and lower diameter is influenced by hole diameter, the interaction between material thickness and hole diameter and interaction between cutting speed and hole diameter. Figure 4 shows, in graphical form, the effects of influential parameters on surface roughness.

It is clear from figures 4 (a and b) that surface finish is improved at high value of cutting speed and low value of feed rate. Figures 4 (c and d) showing effect of interaction between (i) material thickness and nominal hole diameter (ii) feed rate and nominal hole diameter and it can

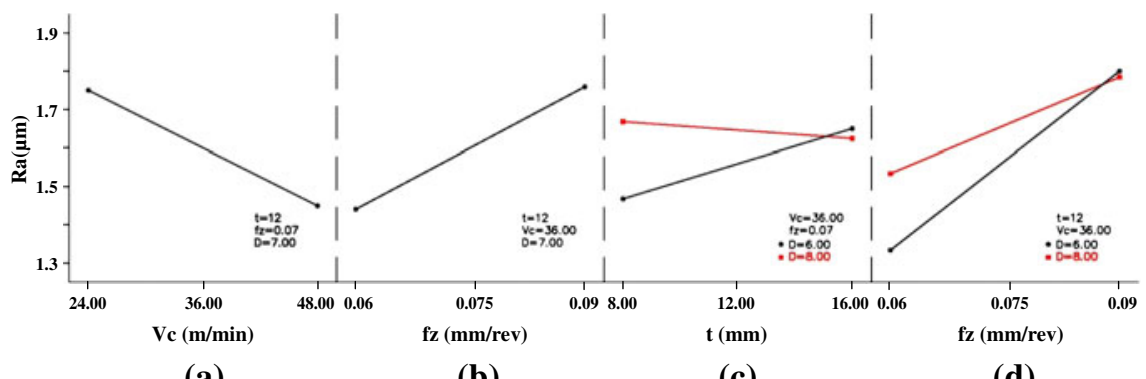

(a)

(b)

(c)

(d)

Figure 4. Factorial plots showing effects of: (a) cutting speed; (b) feed rate; (c) interaction between material thickness and nominal hole diameter; (d) interaction between feed rate and nominal hole diameter upon arithmetic surface roughness $(\mathrm{Ra})$ in drilling process. 


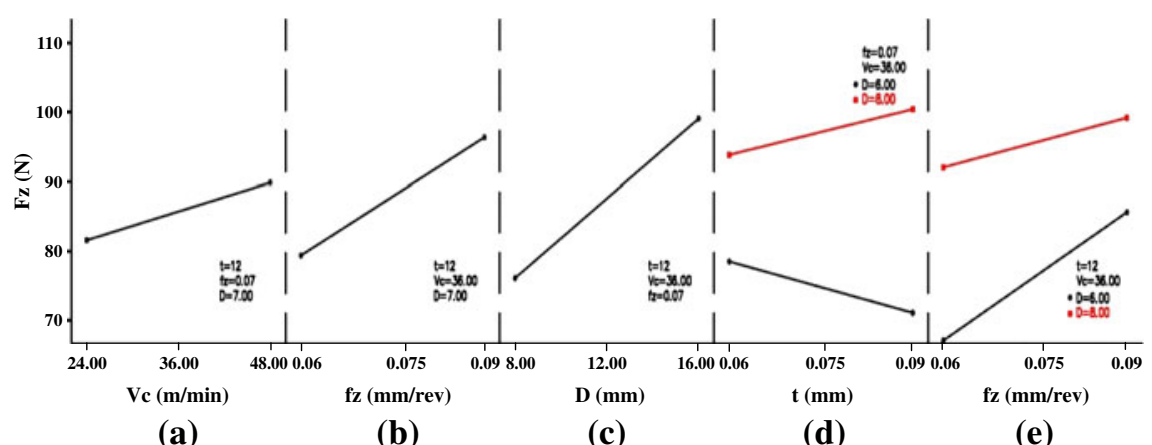

Figure 5. Factorial plots showing effects of: (a) cutting speed; (b) feed rate; (c) nominal hole diameter; (d) interaction between material thickness and nominal hole diameter; (e) interaction between feed rate and nominal hole diameter upon average thrust force $\left(\mathrm{F}_{\mathrm{Z}}\right)$ in drilling process.

be figured out that at high level of material thickness and feed rate the surface finish obtained is almost the same for both hole diameter but at low level of material thickness and feed rate of the surface finish is high as the hole diameter increase. The results indicated that the increase in the feed rate causes increase in the surface roughness of the cutting hole up to $1.75 \mu \mathrm{m}$. The increase in feed rate increased the heat generation and hence, tool wear, which resulted in the higher surface roughness. The increase in feed rate also increased the chatter and produced incomplete machining at a faster traverse, which led to higher surface roughness (Palanikumar 2011).

It is clear from figure 5a that the increase in thrust force with increasing the cutting speed is not too significant due to the higher temperatures produced by the increase in heat generation associated with the low coefficient of thermal conduction together with the low transition temperature of plastics. From figures 5 (b and c) it is clear that the thrust force is maximum at high levels of feed rate and hole diameter. The increase in the feed rate increases the load on the drill, which increases the thrust force in drilling of composites. The interaction plots in figures 5 ( $\mathrm{d}$ and e) show that the effect of hole diameter is significant but it is more significant at

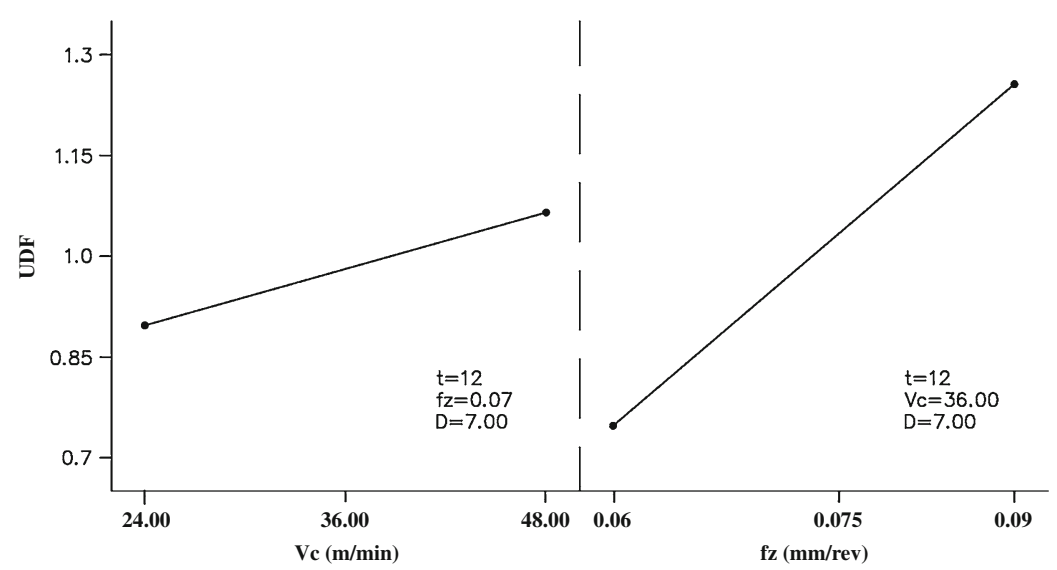

(a)

(b)

Figure 6. Factorial plots showing effects of: (a) cutting speed; (b) feed rate upon delamination factor at upper surface in drilling process. 


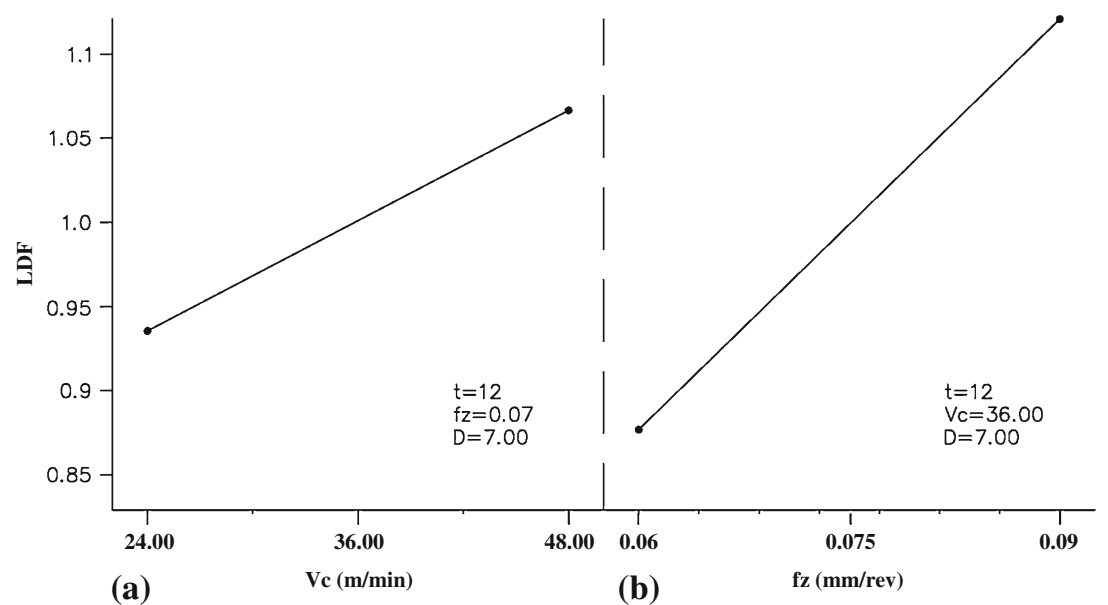

Figure 7. Factorial plots showing effects of: (a) cutting speed; (b) feed rate upon delamination factor at lower surface in drilling process.

the high level of material thickness. The same behaviour was observed in the case of interaction between feed rate and hole diameter. Figures 6 and 7 present effects of the significant parameters upon the delamination factor at upper and lower surface. It is clear from graphs (a and b) in figures 6 and 7 that the delamination is increased more as feed rate increased than in the case of increasing the cutting speed. The increase of feed rate increases the thrust force and delamination in drilling. Thrust force and delamination are the inter-connected phenomenon, in which the increase of thrust force increases the delamination factor and vice versa. Figure 8 shows (in graphical form) the effects of the significant parameters upon the difference between upper and lower diameter. The graph (a) in figure 8 shows that the difference between upper and lower diameter increases as the hole diameter increases, while graph (b) indicates that the difference between upper and lower diameter is high at interaction between the material thickness and high level of hole diameter.

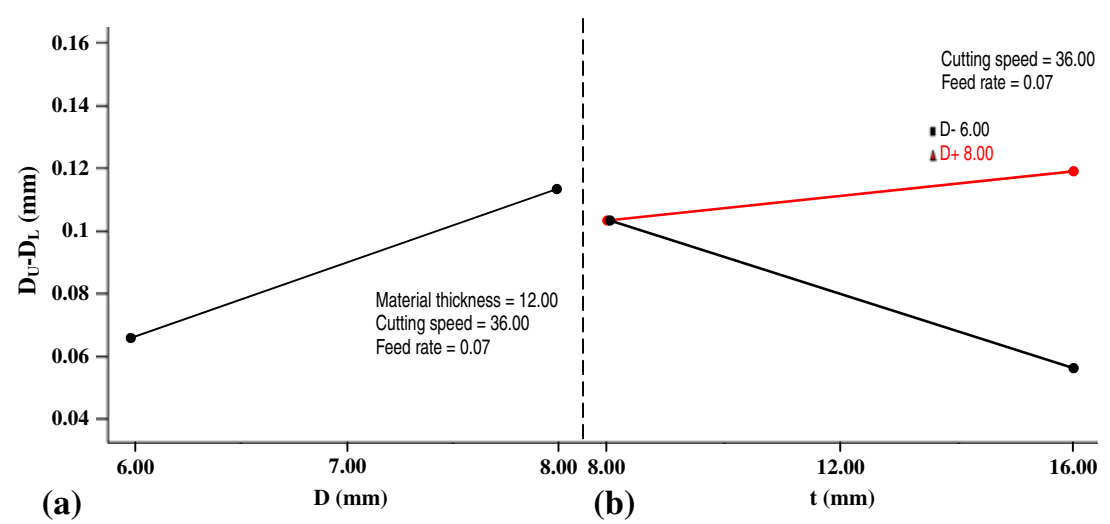

Figure 8. Factorial plots showing effects of: (a) nominal hole diameter; (b) interaction between material thickness and nominal hole diameter upon the difference between upper and lower diameter in drilling process. 
3.1b Analysis and discussion of hole making by milling: Tables 7 and 8 present ANOVA performed on data related to surface roughness, machining force and tensile strength in hole making by milling.

Tables 7 and 8 show that cutting speed and feed rate are affecting factors upon surface roughness while the machining force is significantly affected by feed rate, hole diameter and by the interaction between material thickness and hole diameter and the interaction between feed rate and hole diameter. The upper and lower delamination factors are significantly affected by feed rate, while the difference between upper and lower diameter is affected by feed rate and interaction between feed rate and hole diameter. The table also shows that there is no significant factor on the tensile strength. Figure 9 shows, in graphical form, the effects of influential parameters upon surface roughness. It is clear from the figure that the surface roughness of the cutting hole is increased with the increase of feed rate and decreased with the increase of cutting speed. This is because at higher feed rate, debonding and fibre breakage takes place, i.e., to get better surface finishing it is necessary to apply a high cutting speed and a low feed rate (Paulo Davim et al 2004).

From figure 10, it can be realized that the machining force in the work piece increases with feed rate and decreases with the hole diameter.

It can be noticed from figures 11 ( $a$ and $b$ ) that the delamination is increased at upper and lower surface as the feed rate increased. This is because of debonding and fibre breakage takes place at high feed rate.

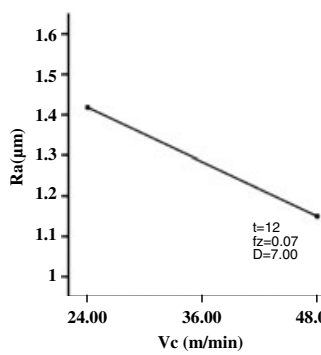

(a)

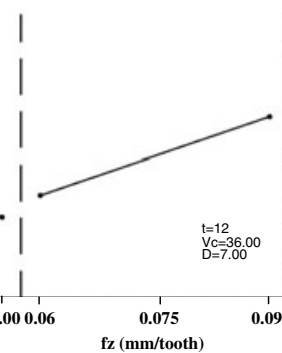

(b)

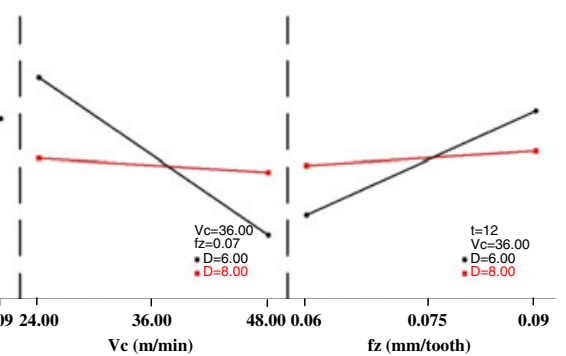

(c)

(d)

Figure 9. Factorial plots showing effects of: (a) cutting speed; (b) feed rate; (c) interaction between cutting speed and nominal hole diameter; (d) interaction between feed rate and nominal hole diameter upon surface roughness in milling process.

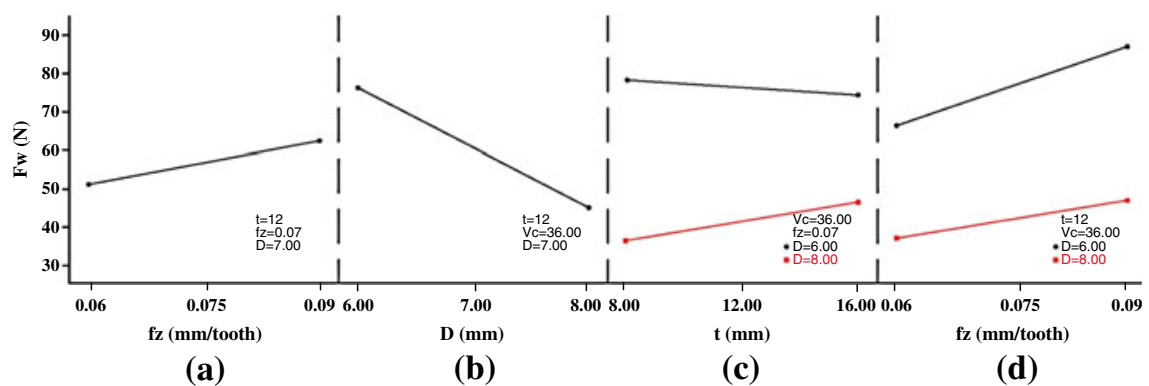

Figure 10. Factorial plots showing effects of: (a) feed rate; (b) nominal hole diameter; (c) interaction between material thickness and nominal hole diameter; (d) interaction between feed rate and nominal hole diameter upon machining force in milling process. 


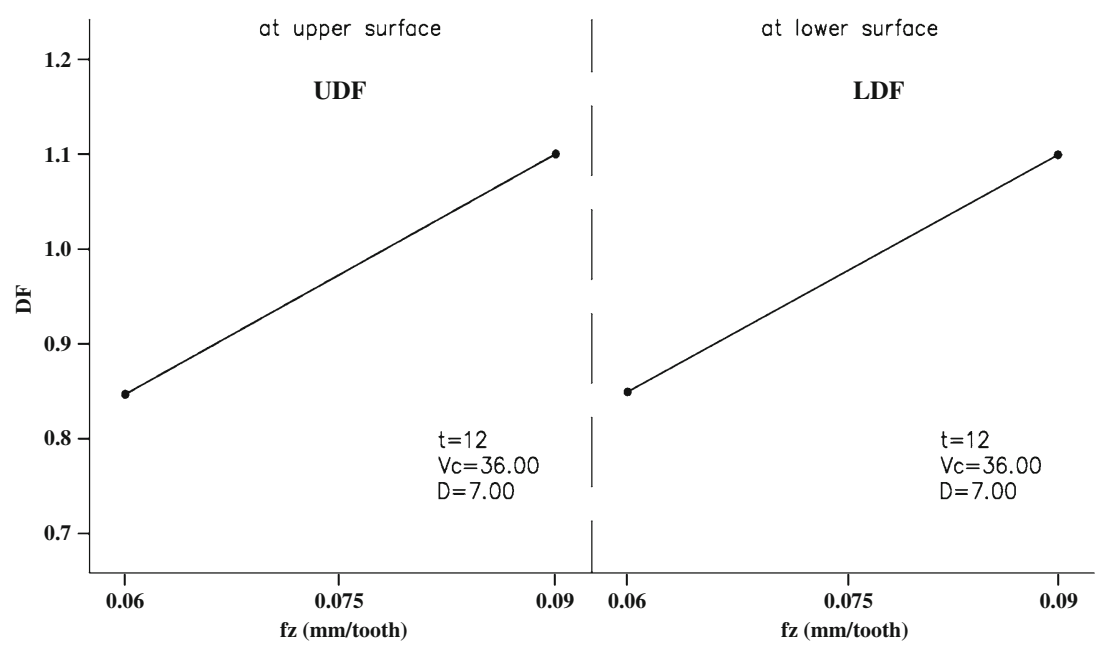

(a)

(b)

Figure 11. Factorial plots showing effects of: (a) feed rate at upper surface; (b) feed rate at lower surface upon delamination factor at upper and lower surfaces in milling process.

It is clear from figures $12 \mathrm{a}, \mathrm{b}$ and $\mathrm{c}$ that the difference between upper and lower diameter is increased as the feed rate and nominal hole diameter increased.

A sample of microscopic pictures for the holes cutting by drilling and milling processes can be shown in figures 13 and 14, respectively. Graphs a and b of figure 13 represent the upper and lower surfaces optical picture of experiment no. 16 which is machined by drilling process. It can be shown from this figure that, $\mathrm{BC} 1$ represents the cut hole diameter while $\mathrm{BC} 2$ represents the diameter that includes the defects in both upper and lower surfaces, respectively. The difference between $\mathrm{BC} 1$ and $\mathrm{BC} 2$ which represent the difference between upper and lower hole diameter is equal to $0.131 \mathrm{~mm}$, while the difference between upper and lower hole diameter, which was cut by milling process as shown in graphs a and $b$ of figure 14 which is equal to $0.027 \mathrm{~mm}$. It means

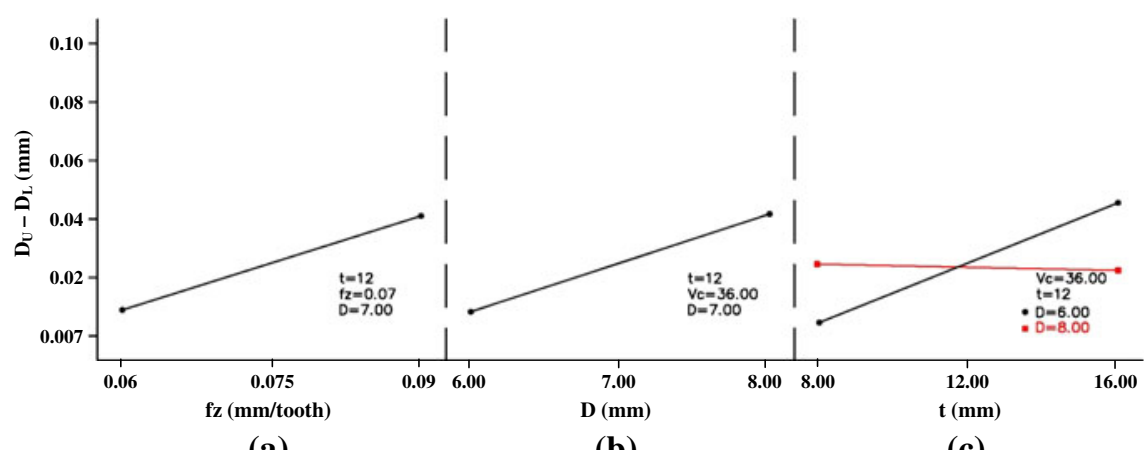

(a)

(b)

(c)

Figure 12. Factorial plots showing effects of: (a) feed rate; (b) nominal hole diameter; (c) interaction between material thickness and nominal hole diameter upon difference between upper and lower diameter in milling process. 


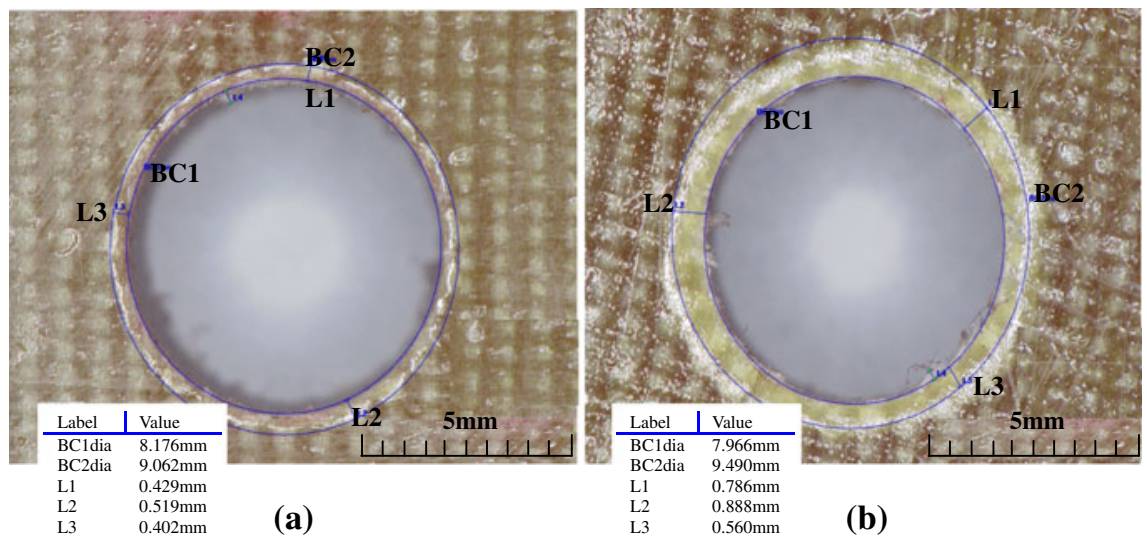

Figure 13. Microscopic pictures for hole no.16, of drilling process (a) upper hole surface (b) lower hole surface.

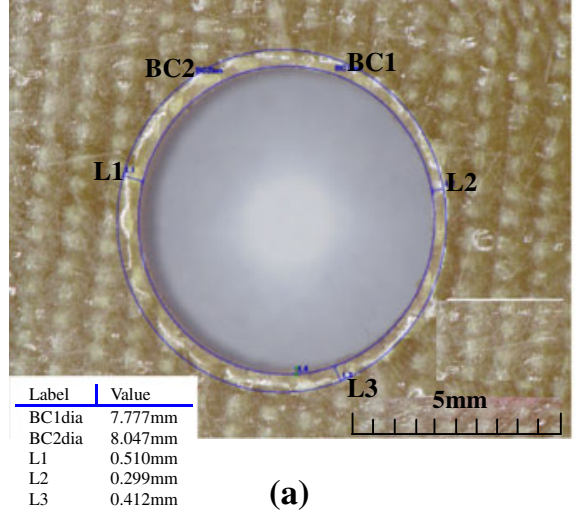

(a)

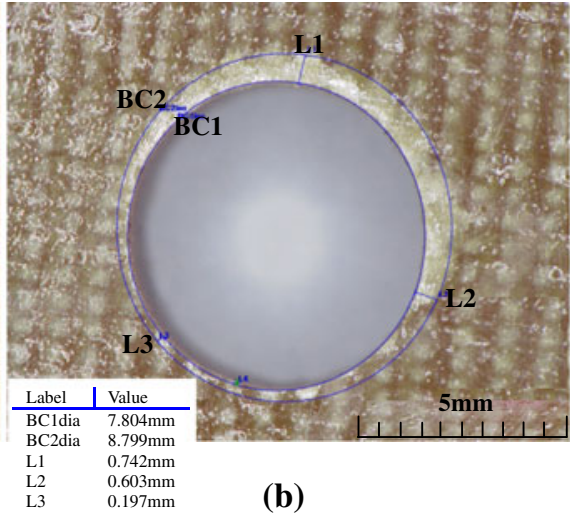

(b)

Figure 14. Microscopic pictures for hole no.16, of milling process (a) upper hole surface (b) lower hole surface.

that the difference between upper and lower hole diameter in the case of milling process is lesser than that in the case of drilling process. This is because the increase in tool wear is minimal due to changes in the spindle speed (Azmi et al 2013).

\section{Numerical optimization}

The drilling and milling processes have been widely used in industry. The two technologies have procured many overlapping applications and it is thus important for the industry to understand both processes, in order to select the optimum method in different situations. The comprehensive knowledge on quality, operating cost and productivity will help the users to judge which cutting process is more appropriate for each type of application. The target of numerical optimization in the present study could be any combination of the following seven objectives: (i) Minimize $\mathrm{R}_{\mathrm{a}}$; 
Table 9. Recommendations and predictions of multi-objective optimization against each set of objectives and comparison with experimental results in drilling process.

\begin{tabular}{|c|c|c|c|c|c|c|c|}
\hline \multirow[b]{2}{*}{ No } & \multirow[b]{2}{*}{ Objectives } & \multicolumn{2}{|c|}{ Fixed parameters } & \multicolumn{2}{|c|}{ Optimized parameters } & \multicolumn{2}{|c|}{ Comparison } \\
\hline & & $\begin{array}{c}\mathrm{t} \\
(\mathrm{mm})\end{array}$ & $\begin{array}{c}\mathrm{D} \\
(\mathrm{mm})\end{array}$ & $\begin{array}{c}\mathrm{Vc} \\
(\mathrm{m} / \mathrm{min})\end{array}$ & $\begin{array}{c}\mathrm{f}_{\mathrm{Z}} \\
(\mathrm{mm} / \mathrm{rev})\end{array}$ & $\begin{array}{l}\text { Predicted } \\
\text { values }\end{array}$ & $\begin{array}{c}\text { Experimental } \\
\text { values }\end{array}$ \\
\hline 1 & $\operatorname{Minimize}\left(\mathrm{R}_{\mathrm{a}}\right)$ & 12 & 7 & 48 & 0.06 & $1.26 \mu \mathrm{m}$ & $1.21 \mu \mathrm{m}$ \\
\hline 2 & $\operatorname{Minimize}\left(\mathrm{R}_{\mathrm{a}}\right)$ & & & & & $1.26 \mu \mathrm{m}$ & $1.21 \mu \mathrm{m}$ \\
\hline \multirow[t]{2}{*}{3} & $\operatorname{Minimize}\left(\mathrm{R}_{\mathrm{a}}\right)$ & & & & & $1.26 \mu \mathrm{m}$ & $1.21 \mu \mathrm{m}$ \\
\hline & \& Minimize $\left(\mathrm{F}_{\mathrm{Z}}\right)$ & & & & & $78.22 \mathrm{~N}$ & $86.4 \mathrm{~N}$ \\
\hline \multirow[t]{2}{*}{4} & $\operatorname{Minimum}\left(\mathrm{R}_{\mathrm{a}}\right)$ & & & 48 & 0.07 & $1.38 \mu \mathrm{m}$ & $1.32 \mu \mathrm{m}$ \\
\hline & \& Maximize (Pr) & & & & & 14.5 hole $/ \mathrm{min}$ & 14.5 hole $/ \mathrm{min}$ \\
\hline 5 & $\operatorname{Minimize}\left(\mathrm{Du}-\mathrm{D}_{\mathrm{L}}\right)$ & & & 24 & 0.06 & $0.058 \mathrm{~mm}$ & $0.045 \mathrm{~mm}$ \\
\hline 6 & $\operatorname{Minimize}\left(\mathrm{F}_{\mathrm{z}}\right)$ & & & & & $76.32 \mathrm{~N}$ & $81.2 \mathrm{~N}$ \\
\hline \multirow[t]{2}{*}{7} & Minimize & & & & & 0.66 & 0.62 \\
\hline & $\left(\mathrm{DFu} \& \mathrm{DF}_{\mathrm{L}}\right)$ & & & & & 0.76 & 0.78 \\
\hline 8 & Maximize (Pr) & & & 48 & 0.09 & 14.5 hole $/ \mathrm{min}$ & 14.5 hole $/ \mathrm{min}$ \\
\hline
\end{tabular}

(ii) minimize $\mathrm{R}_{a}$ and maximize productivity (Pr), simultaneously; (iii) minimize $\mathrm{R}_{\mathrm{a}}$ and minimize $\mathrm{F}_{\mathrm{Z}}\left(\right.$ or $\mathrm{F}_{\mathrm{w}}$ ), simultaneously; (iv) minimize $\mathrm{D}_{\mathrm{U}}-\mathrm{D}_{\mathrm{L}}$; (v) minimize $\mathrm{F}_{\mathrm{z}}$ (or $\mathrm{F}_{\mathrm{w}}$ ); (vi) minimize delamination at upper and lower surfaces.

Tables 9 and 10 present the optimized values (within tested range) of the predictor variables for different combination of the objectives. Last column of the tables show the actual results of the confirmation experiments performed against each optimized combination. The two tables show that low surface roughness can be achieved by cutting at high settings of cutting speed and low settings of feed rate because high level of feed rate causes increasing in the chatter and produces incomplete machining at a faster traverse, which leads to higher surface roughness. The above tables show also, that low values of the difference between upper and lower diameter and low values of damage at the entrance and exit of the cutting hole can be achieved by low

Table 10. Recommendations and predictions of multi-objective optimization against each set of objectives and comparison with experimental results in milling process.

\begin{tabular}{|c|c|c|c|c|c|c|c|}
\hline \multirow[b]{2}{*}{ No } & \multirow[b]{2}{*}{ Objectives } & \multicolumn{2}{|c|}{ Fixed parameters } & \multicolumn{2}{|c|}{ Optimized parameters } & \multicolumn{2}{|c|}{ Comparison } \\
\hline & & $\begin{array}{c}\mathrm{t} \\
(\mathrm{mm})\end{array}$ & $\begin{array}{c}\mathrm{D} \\
(\mathrm{mm})\end{array}$ & $\begin{array}{c}\mathrm{Vc} \\
(\mathrm{m} / \mathrm{min})\end{array}$ & $\begin{array}{c}\mathrm{f}_{\mathrm{z}} \\
(\mathrm{mm} / \text { tooth })\end{array}$ & $\begin{array}{l}\text { Predicted } \\
\text { values }\end{array}$ & $\begin{array}{l}\text { Experimental } \\
\text { values }\end{array}$ \\
\hline 1 & $\operatorname{Minimum}\left(\mathrm{R}_{\mathrm{a}}\right)$ & 12 & 7 & 48 & 0.06 & $1.05 \mu \mathrm{m}$ & $1.16 \mu \mathrm{m}$ \\
\hline \multirow{2}{*}{3} & $\operatorname{Minimum}\left(\mathrm{R}_{\mathrm{a}}\right)$ & & & & & $1.05 \mu \mathrm{m}$ & $1.16 \mu \mathrm{m}$ \\
\hline & \& Minimize $\left(\mathrm{F}_{\mathrm{w}}\right)$ & & & & & $53.86 \mathrm{~N}$ & $53.86 \mathrm{~N}$ \\
\hline \multirow[t]{2}{*}{4} & Minimum $\left(\mathrm{R}_{\mathrm{a}}\right)$ & & & 48 & 0.07 & $1.12 \mu \mathrm{m}$ & $1.18 \mu \mathrm{m}$ \\
\hline & \& Maximize (Pr) & & & & & $12.6 \mathrm{hole} / \mathrm{min}$ & $12.6 \mathrm{hole} / \mathrm{min}$ \\
\hline 5 & $\operatorname{Minimize}\left(\mathrm{D}_{\mathrm{U}}-\mathrm{D}_{\mathrm{L}}\right)$ & & & 24 & 0.06 & $0.006 \mathrm{~mm}$ & $0.01 \mathrm{~mm}$ \\
\hline 6 & $\operatorname{Minimize}\left(\mathrm{F}_{\mathrm{w}}\right)$ & & & 48 & 0.06 & $53.86 \mathrm{~N}$ & $68.5 \mathrm{~N}$ \\
\hline \multirow[t]{2}{*}{7} & Minimize & & & 24 & 0.06 & 0.81 & 0.77 \\
\hline & $\left(\mathrm{DFu} \& \mathrm{DF}_{\mathrm{L}}\right)$ & & & & & 0.85 & 0.86 \\
\hline 8 & maximize $(\operatorname{Pr})$ & & & 48 & 0.08 & 13.42 hole $/ \mathrm{min}$ & 13.42 hole $/ \mathrm{min}$ \\
\hline
\end{tabular}


setting of cutting speed and feed rate, which minimize load on the drill. Finally, minimum cost per hole and maximum production of holes per minutes can be achieved if high setting of cutting speed and feed rate are employed. It was shown that experimental values are fairly close to the predicted values of the objectives and thus the optimization method is valuable.

\section{Conclusions}

This paper was intended to present an experimental investigation related to the drilling and milling processes in hole making of GFRP. A comprehensive statistical analysis was carried out to isolate the effects of major drilling and milling cutting parameters on surface finish, delamination factor at upper and lower surface, difference between upper and lower diameters, thrust and machining force, cost and productivity. Thirty-two tests following full factorial design of experiments were performed on laminated GFRP. The conclusions of the present study were drawn as follow.

(i) Milling cutting process is more suitable than drilling process at high level of cutting speed and low level of feed rate, when the cutting quality (minimum surface roughness, minimum difference between upper and lower diameter) is of critical importance in the manufacturing industry, especially for precision assembly operation.

(ii) In drilling process, average thrust force can be reduced by reducing the cutting speed while in milling, machining force can be reduced by reducing feed rate.

(iii) In both drilling and milling process, productivity can be increased by increasing speed and feed rate.

\section{Acknowledgements}

The authors would like to thank for the help and support provided by the staff of College of Mechanical and Electrical Engineering, Nanjing University of Aeronautic and Astronautic in performing experimental work there.

\section{Nomenclature}

t Material thickness

Vc Cutting speed

$\mathrm{f}_{\mathrm{z}}$ Feed rate

D Nominal hole diameter

$\mathrm{R}_{\mathrm{a}}$ Arithmetic surface roughness

DF Delamination factor

UDF Upper delamination factor

LDF Lower delamination factor

$D_{U}$ Upper surface diameter

$\mathrm{D}_{\mathrm{L}}$ Lower surface diameter

$\mathrm{F}_{\mathrm{Z}}$ Thrust force

$F_{w}$ Machining force

Pr Productivity

$\mathrm{z}$ Number of teeth in end mill. 


\section{References}

Abrao A M, Faria P E, Campos Rubio J C, Reis P and Davim J P 2007 Drilling of fiber reinforced plastics: a review. J. Mater. Process. Technol. 186: 1-7

Azmi A I, Lin R J T and Bhattacharyya D 2013 Machinability study of glass fibre reinforced polymer composites during end milling. Int. J. Adv. Manuf. Technol. 64(1): 247-261

Derringer G and Suich R 1980 Simultaneous optimization of several response variables. J. Q. Technol. 12: $214-219$

El-Sonbaty I, Khashaba U A and Machaly T 2004 Factors affecting the machinability of GFR/epoxy composites. Compos. Struc. 63(3-4): 329-338

Hocheng H and Tsao C C 2005 The path towards delamination-free drilling of composite materials. $J$. Mater. Process. Technol. 167: 251-64

Hocheng H, Puw H Y and Huang Y 1993 Preliminary study on milling of unidirectional carbon fibrereinforced plastics. Compos. Manuf. 4(2): 8-103

http://www.ptli.com/testopedia, Open hole tensile strength of polymer matrix composite laminates ASTM D5766, D5766M, Intertek Plastics Technology Laboratories

Hufenbach W, Dobrzański L A, Gude M, Konieczny J and Czulak A 2007 Optimization of rivet joints of CFRP composite material and aluminum alloy. J. Achiev. Mater. Manuf. Eng. 20: 119-22

Mohan N S, Ramachandra A and Kulkarni S M 2005 Machining of fiber-reinforced thermoplastics: influence of feed and drill size on thrust force and torque during drilling. J. Reinf. Plast. Compos. 24(12): 1247-1257

Mohd Ariffin M K A, Mohd Ali M I, Sapuan S M S M and Ismail N 2009 An optimize drilling process for an aircraft composite structure using design of experiments. Sci. Res. Essay. 4(10): 1109-1116

Palanikumar K 2011 Experimental investigation and optimization in drilling of GFRP composite. Measurement 44: 2138-2148

Paulo Davim J, Reis P and Antonio C 2004 A study on milling of glass fibre reinforced plastics manufactured by hand-lay up using statistical analysis (ANOVA). Compos. Struc. 64: 493-500

Ramulu M, Arola D and Colligan K 1994 Preliminary investigation of effects on the surface integrity of fibre reinforced plastics. In: Eng. Syst. Des. Anal. 2. 64(2): 93-101

Teti R 2002 Machining of composite materials. CIRP Ann-Manuf. Technol. 51: 611-34

Tsao C C 2008 Experimental study of drilling composite material with step-core drill. Mater. Design 29: $1740-1744$

Tsao C C and Hocheng H 2003 The effect of chisel length and associated pilot hole on delamination when drilling composite materials. Int. J. Mach. Tool Manuf. 43(11): 1087-1092

Yang Y Y, Shie J R and Huang C H 2006 Optimization of dry machining parameters for high purity graphite in end-milling process. Mater. Manuf. Process. 21: 832-837 